\title{
EL GÉNERO Y LA PERSPECTIVA EN TOJOLABAL
}

\author{
Carlos LENKERSDORF
}

Centro de Estudios Mayas

\section{El género}

\subsection{La razón de la investigación}

En español, al referirnos a otras personas, decimos él o ella; en tojolabal, al referirnos a las mismas personas, decimos simplemente $y e^{\prime} n$. Una sola palabra es suficiente. A diferencia del español no se señala el género. No nos interesa aclarar si hablamos de una mujer o de un hombre. ¿A qué se debe la diferencia? ¿Cuál es el papel de los gé-

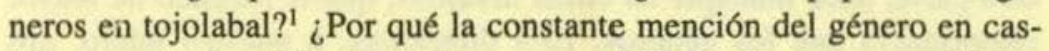
tellano y en otros idiomas indeoeuropeos? He aquí, en pocas palabras, la razón inicial de este trabajo.

Vamos a investigar, pues, el uso y significado del género en el idioma tojolabal, porque esto nos muestra aspectos del idioma que ignoramos si nuestro contexto lingǘstico se restringe al español o a la mayoría de los demás idiomas indoeuropeos. Por ello, pensamos que la indagación nos servirá para entender mejor las lenguas, tanto la maya como la nuestra.

En publicaciones lingüísticas recientes, el tema del género no ha atraído el interés de muchos investigadores. Las feministas representan una excepción muy notable, ${ }^{2}$ porque problematizan el tema del género al hacer preguntas que se solían ignorar y que muchos no se tomaban en serio. Nos referimos, por supuesto, a la predominancia

\footnotetext{
${ }^{1}$ Por el momento dejamos a un lado el género neutro, que no se refiere a personas. Lo trataremos un poco en el apartado 5.

${ }^{2}$ Véase Sally McCollin-Ginet, 1990: 75-78. La autora agrega una bibliografía amplia a su trabajo.
} 
de los hombres y del género masculino, asunto ampliamente difundido en muchos idiomas indoeuropeos. Desde el punto de partida de nuestro trabajo, el enfoque de las feministas es muy instructivo aunque algo limitado, porque el papel de las mujeres y la relación de ambos sexos, reflejada en las lenguas, es sólo un aspecto entre varios dentro de la temática que queremos dilucidar.

De todos modos, la investigación lingüística del tema, por parte de las feministas, enriquece la disciplina porque ha logrado dos cosas: no sólo trata el tema del género de nuevo, sino que lo hace de manera nueva. Gracias a su perspectiva están surgiendo cuestiones relevantes que, hasta la fecha o tal vez por mucho tiempo, no se han visto. El ejemplo de las feministas nos hace observar que una inquietud existencial particular hace aflorar interrogaciones ignoradas o no aceptadas por los demás. Y ésa es una de las formas que produce dos cosas: el surgimiento de nuevas investigaciones y el avance de las ciencias.

Así también ha pasado con nosotros: una inquietud nos ha despertado y nos está impulsando. La señalamos brevemente al comenzar este apartado. Dicho de otro modo, el problema es el siguiente. Los géneros se expresan de una manera marcada y constante en español, a diferencia del tojolabal, que a menudo no los menciona y que, por otra parte, hace hincapié en cosas distintas, que le parecen de mayor importancia que los géneros. Esta diferencia, a nuestro juicio, nos abrirá un nuevo camino en la investigación lingüística del género.

Por lo tanto, aunque el enfoque sea limitado, no nos olvidaremos de los problemas señalados por las feministas. Tanto el papel de las mujeres en el contexto lingüístico y cultural de los tojolabales como el empleo de los géneros nos enseñará cosas de primera importancia de la lengua y comovisión del pueblo maya de los Altos de Chiapas.

Ahora bien, aparte de la bibliografía lingüística podemos buscar información sobre nuestro tema en las gramáticas que, por supuesto, lo explican sin falta, de una manera descriptiva y con algunas referencias históricas, como lo observamos, por ejemplo, en el libro de Martín Alonso. ${ }^{3} \mathrm{La}$ exposición es muy completa, pero el camino de interpretación nos parece algo insuficiente. La razón es que el género, expresado constantemente por los hablantes del castellano, señala realidades socioculturales en las cuales el idioma y los hablantes quieren hacer hincapié, aunque sea inconscientemente.

${ }^{3}$ Véase Martín Alonso, 1968: 284-289, núm. 94. 
Por ejemplo, no es justificado preguntar: ¿por qué se le asigna género a tantas palabras?, ¿cuál es el fundamento de esta asignación marcada? Para poder responder a esta clase de preguntas nos parece necesario trascender el marco netamente lingüístico. Martín Alonso se da perfecta cuenta de los problemas y contradicciones y, por ello, habla "del misterio del género". ${ }^{4}$ Hace referencias a la medicina biológica, al relato de la creación del Génesis, a los griegos, etc., sin salir del enfoque descriptivo. Señala que el tema del género nos cuestiona de un modo inquietante y nosotros no encontramos respuestas. Nos quedamos, pues, en el misterio.

Nosotros, en cambio, pensamos que podemos avanzar algo más en la comprensión del problema. Proponemos ubicar el tema en el contexto de la relación lengua y cosmovisión para tratar de entender mejor el tema en lugar de quedarnos en el misterio. Seguramente, éste no desaparecerá totalmente, pero tenemos la esperanza de hacerlo un poco más transparente. Al terminar la investigación nuestros lectores dirán si hemos cumplido con nuestro proposito.

La relación mencionada entre lengua y cosmovisión nos permite añadir otras razones que nos explican la investigación propuesta. Al profundizar nuestros conocimientos de las lenguas, incluso de la nuestra, otros hechos, a menudo desconocidos, nos abren los ojos para comprender el mundo de los idiomas. Queremos hacer hincapié en que las particularidades del habla van más allá del contexto lingüístico. Nos manifiestan idiosincrasias de las culturas de los hablantes de idiomas diferentes; sobre todo tan diferentes como el castellano y el maya tojolabal. Es decir, el estudio de los idiomas trasciende el contexto lingüístico restringido, según nos proponemos mostrar en el curso de esta investigación. Dicho de otro modo, si logramos entender algo del papel del género en tojolabal, pensamos que, a la vez, captamos también algunos de los fundamentos de la cosmovision tojolabal. Con esto indicamos el camino de la investigación que vamos a seguir. En su desarrollo veremos el fundamento de la relación lengua-cosmovisión.

Ahora bien, sabemos que el tojolabal, idioma hablado en los Altos de Chiapas, se distingue de las lenguas indoeuropeas por pertenecer a la familia de los idiomas mayas. Podemos señalar las diferencias en muchos aspectos al comparar el tojolabal con el castellano. Al hacerlo con respecto al género vemos algunas de las particularidades lingüísticas muy características tanto del tojolabal como del español; particularida-

${ }^{4}$ Ibidem, pp. 285-287. 
des de las cuales, además, en muchas ocasiones no nos damos cuenta, ${ }^{5}$ ni siquiera en nuestro idioma materno.

\subsection{Presencia y ausencia del género}

En castellano el género es de dos o tres clases: el género natural, que nos indica el sexo de personas, animales y plantas; el género gramatical, que asigna uno de los géneros usados a las cosas asexuales; el género común o epiceno, que usa el mismo género para los animales tanto del sexo masculino como del femenino. Se trata, pues, de un fenómeno lingüístico que, en algunos casos, refleja la realidad de los sexos y en los demás parece estar determinado por puras convenciones o arbitrariedades lingüísticas. ${ }^{6}$

Las gramáticas subrayan que, originalmente, en los idiomas indoeuropeos, la diferencia de los géneros no se derivaba de los sexos, sino de lo animado e inanimado. ${ }^{7}$ Muchos mayistas también hablan de la "jerarquía de animación" y le asignan cuatro niveles:

nivel 1: nombres y pronombres independientes

nivel 2: seres humanos o animales antropomorfos

nivel 3: otros animados

nivel 4: inanimados.

Dicen que tienen la función de "evitar la ambigüedad entre qué argumento (sustantivo) es el sujeto y cuál es el objeto". Es decir, la jerarquía sirve para establecer un orden determinado de los elementos sintácticos dentro de la frase. ${ }^{8}$

Podríamos suponer que dicha jerarquía de animación tuviera alguna relación con los géneros, porque los primeros tres niveles, a diferencia del cuarto, podrían tener los géneros. Es decir, los inanimados no pue-

${ }^{5}$ No siempre se trata de problemas ignorados. A veces son preguntas que no queremos aceptar y buscamos razones para considerarlas inadmisibles o no científicas, etcétera.

${ }^{6}$ Véase Sally McCollin-Ginet, 1990: 77. La autora va más allá del inglés o español, porque observa acertadamente la arbitrariedad y convención con referencia a "las clases gramaticales indoeuropeas del género". Véase también Fernando Lázaro Carreter, 1974: 164, 207.

7 Véanse Martín Alonso, 1968: 284, y Harro Stammerjohann, 1975: 171.

${ }^{8}$ Véase Jill Brody, 1990: 462 y 463. Véanse también Terrence Kaufman, 1990: 80 y 81; Thomas W. Larsen, 1990: 323 y 324; Jon P. Dayley, 1990: 337 y 338; Judith Marie Maxwell, 1990: 456 y 457. 
den ser ni femenino ni masculino, a no ser que exista el género gramatical que no hemos encontrado en tojolabal. Nosotros tenemos problemas con la llamada jerarquía de animación en general, y no sólo con referencia a los géneros, de los cuales los mayistas en el contexto indicado tampoco hablan. La razón de nuestros problemas se funda en la diferencia entre "animados e inanimados", que nos parece dudosa con base en la cosmovisión tojolabal, según la cual no hay nada que no tenga corazón, es decir, que no tenga vida. ${ }^{9}$

Tal vez vale la pena recalcar una advertencia, ya hecha con otras palabras. Siguiendo la perspectiva tojolabal estamos insistiendo en la

${ }^{9}$ Entre los cinco autores mencionados en la nota anterior, Jon P. Dailey y Judith Marie Maxwell son los más explícitos en cuanto al tema de la jerarquía de animación en los idiomas mayas. Por la importancia del asunto, lo trataremos en esta nota para no cargar el texto con cuestiones polémicas. Se habla de la jerarquía de animación en el contexto del orden de los elementos sintácticos dentro de la frase. Aquello que nos causa poblema es el "nivel de lo inanimado", por todo lo que implica tanto con referencia a los géneros como en el contexto sintáctico. Por eso, enfocamos las afirmaciones de los investigadores sólo con referencia a la citada jerarquía que tiene repercusiones profundas con respecto a la cosmovisión de los tojolabales, a la orientación de las investigaciones que, seguramente, tendrá repercusiones en la interpretación del mundo de los pueblos mayas en general. Maxwell (p. 457) cita varias frases-ejemplos para demostrar que en chuj no se puede decir "El zacate mató al caballo". Dice que la razón es que el zacate es menos animado que el caballo. Pocas líneas más adelante, sin embargo, tiene que conceder que sí se puede decir la frase dentro de "los textos narrativos, una vez establecido el enfoque del episodio". La argumentación no la consideramos muy convincente, puesto que la frase descontextualizada nos parece algo artificial y no sirve muy bien para fundamentar la jerarquía de animación. Dayley (p. 337), en cambio, no nos ofrece ejemplos, sino que enumera la escala de representantes de distintos grados de animación. En la cúspide están, sobre todo, los seres humanos. En cuanto a los inanimados dice “.... ej. son comunes fuego, viento, agua y terremotos, como agentes poderosos inanimados". Tenemos que preguntar de dónde el autor obtiene la información de que los elementos citados son inanimados. No lo dice. A nuestro juicio las afirmaciones del autor reflejan la perspectiva occidental moderna que se diferencia seguramente de la maya y amerindia. Para los tojolabales no hay nada que no tenga corazón, es decir, que no tenga vida; por ende, nada es inanimado. Por ello, dialogan con los animales y las plantas como lo documentamos en un libro por publicar cuyo título será, Los hombres verdaderos, voces testimoniales. Por la misma razón saben del corazón de los cerros y de las rocas y lo respetan. Y, también por la misma razón, piden perdón del fuego maltratado, del tenamastle no respetado, etc. ¿Cuál es, pues, la base de la afirmación de hablar de lo inanimado? Para terminar, nos parece muy importante que en las investigaciones tratemos de emplear y encontrar categorías que tienen sus fundamentos en la cosmovisión de los hablantes. Más adelante en nuestro trabajo veremos que en casos marcados, aunque tal vez regionales, se les asigna personalidad a las cosas "inanimadas". Sobre la animación de las "cosas" véase el Popol Wuj, edición de Albertina Saravia E. (1992: 14). Nos referimos a la venganza de los comales, las ollas y los tenamastes que castigaron a los hombres hechos de madera. 
presencia de la vida en todas las cosas, por la importancia que esto tiene y por sus repercusiones metodológicas, semánticas y culturales muy profundas. Al escoger como ejemplo el estudio de los géneros en el idioma tojolabal, veremos que, a menudo, los señalamientos de los géneros van mucho más allá de lo esperado y del marco lingüístico. Por ello, afirmamos que los datos de la lengua tendrán que enseñarnos y llevarnos por el camino de aquellos que se llaman hombres verdaderos. Por lo tanto, consideramos necesario orientar la investigación de cualquier tema, de manera tal que el punto de partida sea la perspectiva tojolabal y no la nuestra.

Empecemos con el tema escogido y presentemos una serie de ejemplos que nos permiten llegar a conocimientos fundados en la misma lengua. Vamos a ofrecer los ejemplos con una traducción al castellano que no pretende ser literal, sino que nos da el significado correspondiente en español. No nos metemos en detalles gramaticales para no desviarnos de la exposición. ${ }^{10}$

(1) ja 'ixuki 'la mujer'

(2) ja winiki 'el hombre'

(3) jun 'ak'inte' 'una mesa, una tabla'

(4) jun te' 'un árbol'

(5) ja tzamal nichim 'la flor bonita'

(6) ja tzamal ju'un 'el libro bonito'

(7) ye ' $n$ 'él, ella, ello'

(8) ke'ntik 'nosotros, nosotras'

(9) ja misi 'el gato, la gata'

En todos los ejemplos dados notamos que el tojolabal, a diferencia del castellano, no emplea formas diferentes, desinencias o artículos, para señalar los géneros. Podemos decir que 'ixuk 'mujer' y winik 'hombre' indican los géneros de por sí, porque representan el llamado género natural. Es decir, 'ixuk 'mujer' y winik 'hombre' señalan por su sexo el género femenino o masculino, respectivamente. En ambos idiomas, las palabras de (1) y (2) se diferencian por raíces distintas. Para el ejemplo (9), sin embargo, donde se puede esperar también la indicación del género natural, no se hace. El señalamiento del género, por decirlo así, está ausente. En los ejemplos (3) al (6) observamos el género gramatical del

${ }^{10} \mathrm{~A}$ los interesados en estos temas les mencionamos nuestro libro recientemente publicado. Lenkersdorf, 1994: passim. 
castellano, que en tojolabal no suele usarse. Más adelante veremos ejemplos del tojolabal con referencia al género de "cosas asexuales", si se nos permite el término. En su lugar trataremos de explicarlos. Por el momento, en general afirmamos que el género gramatical no existe en tojolabal. La asignación del género a cosas que nos parecen asexuales manifiesta excepciones, posiblemente regionales. La explicaremos más adelante.

El ya mencionado ejemplo (9) nos enseña otra cosa. Mis puede referirse a 'gata' o 'gato'. En el ejemplo tojolabal, sin embargo, el género no se indica. Con todo esto no queremos decir que el tojolabal no sepa distinguir entre animales machos y hembras, sino que lo hace de manera distinta del español. Este ejemplo nos enseña una diferencia fundamental. Al hablar de animales o en el contexto del reino animal, la referencia a una clase de animales precede a la indicación del género. Ésta requiere que se le agregue una palabra adicional para señalar el sexo. La pura referencia al animal, por lo general, no nos dice si es hembra o macho. ${ }^{11}$ Dicho de otro modo, en el contexto tojolabal la referencia al género o sexo de los animales no suele tener prioridad.

Se puede pensar que mis es epiceno o de género común como, por ejemplo, búho, escarabajo, rata en español. Si aceptamos esta idea, entonces tenemos que afirmar que en tojolabal casi todos los animales son de género epiceno y no sólo un grupo reducido de éstos como lo es en castellano. La suposición no nos parece probable porque el género de los animales casi siempre se señala de manera diferente y no por el puro nombre. La ampliación del grupo de género epiceno para incluir la gran mayoría de los animales no es justificada, por la razón siguiente. Al hablar de animales la referencia al género es, muy probablemente, asunto secundario, por ello no se hace. Si interesa hacerlo, se indica mediante palabras adicionales. Vamos a ver esta clase de indicaciones en el apartado 2 de este trabajo.

Quedan los ejemplos (7) y (8) de los pronombres personales. En castellano siempre marcan la diferencia del género, cosa que no se hace en tojolabal. Con respecto al (9) dijimos que la indicación del género es asunto, probablemente, secundario. Lo mismo podemos afirmar con referencia a los pronombres en los ejemplos (7) y (8). Sobre todo en cuanto al nosotros, veremos más adelante ${ }^{12}$ que hay otro aspecto que desde la perspectiva tojolabal tiene prioridad sobre la indicación del género.

${ }^{11}$ Una de las excepciones es la siguiente. 'ajtzo 'guajolote macho', kolko 'guajolote' (hembra o macho).

${ }^{12}$ Véase el subapartado 4.2. 
Los ejemplos nos han enseñado que, a diferencia del castellano, el tojolabal no suele señalar el género mediante desinencias o artículos. La mayoría de los sustantivos no nos dicen cuál es el género. Tampoco lo hacen los pronombres. Algunos sustantivos indican de por sí el género natural (1) y (2) y lo hacen tanto en español como en tojolabal. Concluimos que, a diferencia del castellano, para el tojolabal la indicación del género no tiene mucha prioridad.

\subsection{El género natural}

Hay toda una serie de nombres cuyo género es obvio. No necesita ningún marcador particular para indicarlo. No nos referimos sólo a las ya mencionadas palabras 'ixuk y winik, cuyo género es evidente, ni tampoco exclusivamente a los nombres de parentesco. También hay otras palabras que de por sí implican el género. Vamos a presentar algunas.

(10) 'ixawal 'patrona'

(11) 'ajwalal 'patrón'

(12) xinan 'ladina, mujer acomodada, rica, explotadora'

(13) jnal 'ladino, hombre acomodado, rico, explotador'

(14) me 'jun 'anciana'

(15) tatjun 'anciano'

(16) 'ak'ix 'muchacha', '(una) joven, soltera'

(17) kerem 'muchacho', '(un) joven, soltero'

(18) me'xep 'abuela'

(19) tatawelo 'abuelo'

(20) che 'um 'esposa'

(21) tatam 'esposo'

(22) nanal 'mamá, madre'

(23) tatal 'papá, padre'

Al comparar los ejemplos en los dos idiomas, notamos que en español, a excepción de mamá y papá, ${ }^{13}$ cada uno de los demás pares tienen una raíz común cuyo género se distingue por las desinencias $(-a,-o)$ o por el artículo indefinido (una, un) en los ejemplos (16) y (17). Los ejemplos (1) y (2) nos mostraron que el artículo definido desempeña

${ }^{13}$ Podemos agregar los derivados: madrina, padrino; comadre, compadre; madrastra, padrastro, etcétera. 
también el papel de indicador del género. Por ello, afirmamos que en castellano, artículos y sufijos sirven de indicadores del género. Las raíces, por lo general, son las mismas y no se diferencian a causa del género que se indica por las maneras señaladas.

En tojolabal, en cambio, la diferencia ya se da a partir de diferentes raíces. El género va implícito en lo que cada persona representa. No hay que agregarle nada para señalar el género. No hace falta ni sufijo ni artículo. Dicho de otro modo, todos estos ejemplos señalan el género natural y no se trata sólo de los términos de las relaciones de parentesco representadas por los ejemplos (18) al (23).

Hay otras palabras que señalan lazos familiares sin indicar el género, por ejemplo, $b$ 'aluch 'cuñada, cuñado'. En estos casos, si queremos mencionar el género, tenemos que señalarlo de otra manera. Lo veremos en el subapartado 1.5. Antes de explicarlo nos toca enfocar otro aspecto de la temática del género.

\subsection{El género de los progenitores}

Hay expresiones que no nos indican el género de la persona cuyo señalamiento nos parece un asunto necesario si no obvio, es decir, según nuestro modo de pensar en español $u$ otros idiomas indoeuropeos. Se nos dice otra cosa, considerada, evidentemente, de mayor interés desde la perspectiva tojolabal.

Veamos los ejemplos que requieren algunas explicaciones. La palabra - unin corresponde tanto a 'hija' como a 'hijo', pero sólo puede serlo de un papá, de un varón o macho (al hablar de animales). Por ello, el prefijo agencial empleado $\left(=\operatorname{pref}_{\mathrm{A}}\right)^{14}$ nos refiere al padre. Por ejemplo, yunin 'su hija, su hijo'. Es decir, el género se indica con toda claridad, pero no es el del producto de la procreación sino el del progenitor. Notamos una diferencia bien interesante. En español y otros idiomas indoeuropeos al hablar de una persona en cuanto a su procedencia familiar vemos o enfocamos el producto, lo nombramos y, por ende, señalamos su género, 'hija' o 'hijo'. Es muy importante que nos demos cuenta de que el "nombramiento" depende de lo que vemos. Subrayamos el hecho de que es la visión perspectivista que determina la selección de la palabra que enunciamos.

${ }^{14}$ Para la terminología de los conceptos gramaticales, véase Lenkersdorf, 1994: passim. 
Nos espera una sorpresa al analizar el idioma mayense. Es decir, desde la perspectiva tojolabal, al hablar de la misma persona no vemos el producto sino al productor, lo nombramos y, por ende, señalamos su género. El del producto, en cambio, no se señala inmediatamente. Requiere una aclaración adicional que se nos da si la queremos. Insistimos en la diferencia fundamental de ver o percibir la realidad (de personas o cosas). La clase de percepción determina el término que escogeremos. No podemos exagerar la diferencia mencionada. Por ello, será necesario explicarnos con más detalle.

Hablamos del ver y lo escribimos en cursivas. Nuestra hipótesis es que nombramos las cosas según las vemos y la vista está condicionada por nuestra perspectiva. En el ejemplo dado, los hispanohablantes ven a la misma persona que los tojolabales pero ambos, conforme a sus perspectivas correspondientes, no perciben los mismos aspectos, los mismos rasgos. Dicho de otro modo, la diferencia de la cual hablamos es la de perspectivas.

Ahora bien, al decir que ven o que vemos no nos referimos necesaria o exclusivamente a los ojos. Tal vez es mejor decir percibimos, porque se trata de captar aquello que nos impresiona y a lo cual le damos prioridad. Dicho de otro modo, nuestra percepción trabaja de modo seleccionador. Hay rasgos que el "colador de percepción" deja pasar, y hay otros que excluye. Por consiguiente, cada uno verbaliza las cosas que ve, pero no en cuanto individuo sino en cuanto miembro de la sociedad a la cual pertenece y que lo condiciona desde su nacimiento.

Sabemos muy bien y por experiencia que si no vemos como ven nuestros paisanos, nos consideran locos o algo por el estilo y corremos el peligro de que no nos acepten en la sociedad, que nos pongan en escuelas para retrasados mentales o que nos encierren en el manicomio y nos privan de la herencia. La historia sabe de muchos testimonios de los tratamientos dados a los "locos".

$\mathrm{Al}$ encontrarnos sólo en el contexto limitado del idioma de nuestra sociedad o de las sociedades dominantes, no nos damos cuenta de nuestra acción de nombrar las cosas según las vemos, es decir, de nuestro perspectivismo excluyente. Por ejemplo, unos dicen hijo, otros fils, otros son, otros Sohn, otros filius, otros ben, otros ibn y así por el estilo. En todos estos ejemplos de idiomas indoeuropeos y semíticos notamos el mismo enfoque: vemos al procreado en primer lugar e inmediatamente le asignamos el género correspondiente. Si queremos mencionar a los progenitores, les damos el segundo lugar y, por supuesto, les asignamos el género correspondiente también (madre o padre). Dicho de otro 
modo, nuestra cosmovisión es parcial, es unilateral al vivir sólo en el contexto de nuestra cultura, por amplia que sea. No tenemos una visión completa de la realidad, nuestros sentidos sirven de coladores que admiten unas cosas sin admitir otras. El reto es si nos damos cuenta de este hecho y lo tomamos en consideración. Los "coladores" nuestros nos convierten en provincianos, inconscientes de nuestro provincialismo.

Nosotros afirmamos que son las distintas perspectivas que nos permiten explicar las diferencias que encontramos en muchas ocasiones y que nos ayudan a entender mejor las maneras de ver el mundo, quiere decir las cosmovisiones, tanto del tojolabal como del español.

Expusimos el asunto con algún detalle, porque es la primera vez que, en este trabajo, nos encontramos con el problema. Al analizar, de modo profundo, idiomas no relacionados en sus orígenes, como el tojolabal y el español, encontramos constantemente diferencias fundamentales que nos hacen ver cosmovisiones desiguales que nos muestran las perspectivas marcadamente distintas de los hablantes.

La diferencia de las cosmovisiones nos enseña otra cosa. La realidad que vemos y que podemos comprobar y, en otras ocasiones, medir, cuantificar, etc., es la realidad conforme a nuestra perspectiva que, a su vez, es selectiva al excluir algunos elementos y admitir otros. Por ello, la realidad que percibimos no es la única. Por la misma razón, no podemos generalizar nuestros conocimientos de la realidad. No son universales sino limitados por nuestra perspectiva. ${ }^{15}$

El ejemplo explicado de -unin nos ha enseñado un poco del perspectivismo tanto de la cosmovisión como de los conocimientos nuestros. Algunos lectores pueden pensar que el ejemplo de -unin no es suficiente para dar fundamentos sólidos a nuestro argumento. Afirmamos que el ejemplo escogido no es de ninguna manera el único. Hay muchos más. De algunos nos damos cuenta; otros, en cambio, esperan que los "descubramos"; mejor dicho, que cobremos conciencia de ellos. En cuanto a elementos conocidos mencionamos, por ejemplo, el "hecho" de que, para los tojolabales, no hay nada que no tenga corazón, la percepción diferente de los colores, ${ }^{16}$ la diferente lógica reflejada en

${ }^{15} \mathrm{El}$ tema señalado mediante las perspectivas relativas según se manifiestan en los idiomas conforme al ejemplo expuesto de yunin/yal, 'hija, hijo' merece una exposición más detallada que presentaremos en otra ocasión. Aquí, además, queremos hacer una breve referencia a otro problema posible. La relatividad de la cosmovisión puede tener repercusiones para la relatividad de la realidad. Es decir, es posible que en ocasiones determinadas no veamos la misma realidad.

${ }^{16}$ Nos referimos a la diferencia conocida de verde-azul -ya $a x$ en tojolabal y términos correspondientes en otros idiomas mayas. Véase también Jane H. Hill, 1990: 27-29. 
la sintaxis. ${ }^{17}$ Otros amerindios hacen hincapié en la misma diferencia de perspectivas y nos llaman la atención para que nos demos cuenta del problema cuyas consecuencias profundas nos tocan a todos nosotros. Presentamos un testimonio que consideramos representativo.

Hemos vivido en este lugar por mucho tiempo, por muchísimo tiempo; queremos decir, desde aquellos tiempos cuando el mundo no tuvo la forma actual. De los antepasados aprendimos que somos partícipes muy pequeños de este universo tremendo, compañeros de viaje con todos los animales, las plantas y las aguas. Todos formamos parte de todo. No podemos ni descuidar ni destruir este hogar nuestro. $\mathrm{Y}$ ahora queremos platicar con aquellos que son incapaces de VER EL MUNDO DE ESTA MANERA. Queremos decirles que juntos somos responsables del barco en el cual estamos navegando. ${ }^{18}$

Subrayamos las diferencias de los idiomas para darnos cuenta de las repercusiones de las investigaciones lingüísticas. Al limitarnos al marco restringido de las lenguas, excluimos el marco referencial de los idiomas que nos sirven a todos nosotros para nombrar el mundo conforme a las perspectivas socioculturales y políticas de nosotros. De este modo se explican cosmovisiones distintas y las lenguas nos sirven de entrada para comenzar a captar esas "visiones de la realidad". Culturas muy diferentes con los idiomas correspondientes nos dan, pues, la posibilidad de ampliar la comprensión de la realidad que vivimos. Este trabajo no es el lugar de profundizar mucho en el tema porque nos faltan aún bastantes elementos. ${ }^{19}$ De todos modos, queremos subrayar que, a nuestro juicio y según las explicaciones dadas, la investigación lingüística trasciende los límites restringuidos de las lenguas.

Avancemos al segundo ejemplo que representa, por decirlo así, una imagen refleja del primero. Es instructivo para que nos demos cuenta de que el caso de -unin no es el único. Hay la palabra -al que corresponde a 'hija' o 'hijo', pero sólo puede serlo de una mamá, de una mujer. Por eso debe llevar el prefijo agencial. Por ejemplo, yal 'su hija, su hijo'.

${ }^{17}$ Véase Carlos Lenkersdorf, 1994: 129-141.

${ }^{18}$ Alocución del hermano Ailton, indio krenak del Amazonas, en una reunión internacional en Londres, Inglaterra. Véase Mirella Ricciardi, 1991: 10. La traducción y las versalitas son nuestras.

${ }^{19}$ Tenemos un libro ya terminado que enfoca el tema con muchas de sus implicaciones. Sólo falta encontrar una casa editorial. 
De hecho los dos sustantivos no se usan sin prefijos agenciales. ${ }^{20} \mathrm{En}$ el contexto tojolabal, no se puede hablar de ninguna hija y de ningún hijo sin hacer la referencia necesaria a la mamá o al papá. Por ende, cada uno de ambos sustantivos siempre desempeña el papel de un nombre subordinado a otro sustantivo cuyo prefijo lleva. Por ejemplo,

(24) ja yal ja nanali 'el hijo (la hija) de la mamá'

(25) ja kunini 'mi hijo' o 'mi hija' (dice un papá)

Explicación: nanali, representada por el prefijo $y$-, desempeña la función del sustantivo subordinador en el (24). En el ejemplo siguiente el prefijo $k$ - sustituye la $y$ - y se refiere, por supuesto al papá.

\subsection{El género señalado}

Si queremos aclarar el género lo hacemos mediante indicadores genéricos. Los ejemplos siguientes nos muestran los más comunes con respecto a personas.

(26) yunin winik 'su hijo' [de un papá no mencionado]

(27) kunin 'ak' $i x$ 'mi hija (hijita)'21 [dice el papá]

(28) yal winik 'su hijo' [de una mamá no mencionada]

(29) moso 'ixuk 'sirvienta'

(30) moso kerem 'mozo'

(31) 'a 'tijum 'ixuk 'obrera'

(32) 'a 'tijum winik 'obrero'

Los ejemplos nos muestran que el género femenino se indica por 'ak'ix o 'ixuk, el masculino por kerem o winik. Los sustantivos ' $a k$ ' $i x \mathrm{y}$ kerem se refieren a personas jóvenes o recientemente casadas. Las palabras 'ixuk y winik, en cambio, pueden designar a personas de mayor edad o a mujeres y hombres de cualquier edad, si se quiere enfatizar solamente el sexo de ellos. Por ejemplo,

(33) 'alatz 'ixuk 'nena'22

${ }^{20}$ También puede emplearse el adjetivo agencial -ala en su lugar. Por ejemplo kala 'unin 'mi querido hijo, mi querida hija' (dice un papá).

${ }^{21}$ ' $a k$ ' $i x$ se refiere a una muchacha joven. De ahí la traducción posible de 'hijita'.

22 'alatz quiere decir 'lactante, recién nacido, bebé'. No nos indica el sexo. 
Los números (29) y (30) nos muestran la adopción de la palabra castellana mozo, que se usa para ambos sexos. En este caso como en otros no se suele usar el sufijo - $a$ para referirse a la 'moza'. ${ }^{23}$ Esta diferencia se expresa por winik, 'ixuk o por otros sustantivos correspondientes.

\subsection{La función sintáctica}

¿Cuál es la función sintáctica de los sustantivos que designan el género? Es posible que los indicadores del género modifiquen los nombres moso, 'a'tijum, 'alatz, etc., o que éstos, a su vez, modifiquen los nombres que indican el sexo. Es decir, cualquiera de las dos clases de sustantivos puede desempeñar la función de atributo para modificar al sustantivo-compañero. ¿Cuál de las dos posibilidades es la más acertada?

Empecemos con el ejemplo (26) yunin winik 'hijo' de 'un padre no mencionado'. Podemos traducir mejor 'su hijo'. Es muy importante darnos cuenta de que el prefijo agencial $y$ - no se refiere a winik. ${ }^{24}$ Es decir, la expresión no suele corresponder a 'su hijo de un hombre'. El prefijo agencial se refiere, pues, a otra persona no mencionada. En los ejemplos siguientes de (34) y variantes veremos la construcción de la frase que corresponde a 'su hijo del hombre'.

El ejemplo (26) habla, pues, de un winik que tiene la cualidad de ser hijo de alguien. Dicho de otro modo, yunin desempeña la función de atributo que modifica el nombre winik. ${ }^{25}$ Ubiquemos el ejemplo en el contexto de una frase para mejor entenderlo. Con el mismo propósito vamos a construir también frases relacionadas, para contrastar las estructuras sintáctico-semánticas que nos van a mostrar otra posibilidad de explicar el (26).

(34) ja 'ni ja yunin winik ja nikolasi. 'Este (es) el hijo de Nicolás'. (34a) ja yunin ja winiki. 'La criatura ${ }^{26}$ del hombre'.

${ }^{23}$ Por la misma razón se puede decir kala 'ermano chepa '¡hermanita Josefa!' En tiempos recientes la influencia del español de la sociedad dominante ha producido el uso de formas femeninas, sobre todo en palabras poco tojolabalizadas entre los jovenes escolarizados. Así se habla de 'ermana, soltera, etcétera.

${ }^{24}$ Hay que decir que, por lo general, la referencia no es a 'un hijo de un hombre'. En casos determinados y excepcionales, según el contexto, el giro puede referirse a tal hijo.

${ }^{25}$ En otro trabajo explicaremos la construcción y las reglas de los compuestos.

${ }^{26}$ Puede ser mujer u hombre. 
(34b) ja'ni ja yunin 'ixuk ja winiki. Ésta '(es) la hija del hombre'. (34c) ja yunin ja nikolasi. 'La criatura de Nicolás'.

Explicaciones: el (34) y el (34b) representan estructuras paralelas. El prefijo agencial $y$-representa a ja nikolasi (34) o a ja winiki (34b), respectivamente; yunin winik y yunin 'ixuk forman unidades en las cuales yunin es atributo de winik o de 'ixuk. Si optamos por esta solución, lo hacemos porque, por lo general, el atributo precede al sustantivo.

En el número (35) y siguientes, además, veremos otros ejemplos que corroboran esta opción. Los demás compuestos de (27) al (33) los podemos explicar de la misma manera. El género se indica por un sustantivo pospuesto que, a su vez, se modifica por los nombres que le preceden. Esta clase de compuestos se construye según una de las reglas de la formación de compuestos. ${ }^{27} \mathrm{El}$ (34a), en cambio, nos deja ver el contraste si el sustantivo que sigue lleva artículo. En este caso el prefijo agencial $y$ - lo representa. El cambio semántico es obvio. El (34b) combina elementos de (34) y (34a). El prefijo agencial $y$-representa a ja winiki como lo hace también en (34a); el sustantivo 'ixuk, en cambio, sustituye a winik de (34) para indicar el género de yunin.

Ahora bien, si explicamos la construcción a partir de (34c), ampliada por (34) podemos optar por otro tipo de construcción. Es decir, winik modifica la clase de yunin que Nicolás tiene porque nos indica el sexo o género. Esta interpretación se explica, sobre todo, por razones semánticas y no por las estructuras sintácticas acostumbradas. Presentamos las dos opciones como posibles. Al enfocar los compuestos en otro trabajo, tendremos que regresar al asunto y veremos si sólo una de las dos opciones prevalece.

\subsection{Del género al cosmos}

Finalmente hay otra manera para indicar el género en el contexto de personas. Vamos a ver algunos ejemplos escogidos.

(35) ja jnantik 'ixaw 'nuestra madre luna' (jnantik 'ixawa) $)^{28}$

${ }^{27}$ Véase la nota 25.

${ }^{28} \mathrm{El}$ giro entre paréntesis se usa a veces, sobre todo en un contexto de lenguaje de más consideración para expresar el respeto. El sufijo - $a$ se explica, a menudo, porque se agrega al dirigir la palabra a alguien, sobre todo en saludos. Por ejemplo, sa'n kala nana 'buenos días, nanita'; wajkona 'adiós' (es decir, 'voy'). 
(36) ja snan 'ixaw 'la madre luna'

(37) ja swaw k'ak' $u^{29}$ 'el padre sol'

(38) ja jnantik lu'um 'nuestra madre tierra'

(39) ja jnantik walalupe 'nuestra madre Guadalupe' (la Virgen de Guadalupe)

(40) ja jnantik margarita 'Santa Margarita' 30

(41) jtatik jesucristo 'nuestro padre Jesucristo' ${ }^{31}$

(42) jtatik pagre eterno 'Santo Padre Eterno'32

Todos estos ejemplos pertenecen al ámbito cultural-religioso. Tanto a la Tierra como a la Luna y a la Virgen se les considera Nuestra Madre. En el contexto tojolabal la religión de la costumBre y la recibida por la evangelización se pueden, obviamente, complementar. ${ }^{33} \mathrm{La}$ Madre no representa una persona singular sino que, desde la perspectiva tojolabal, todos tenemos una pluralidad de Madres y también de Padres.

1.7.1. Madres y Padres de todos nosotros. Al hablar de los géneros nos encontramos con una pluralidad de madres de los tojolabales LA Luna, la Tierra y la Guadalupana, la Santa Margarita y otras más. Todas ellas se encuentran en el mismo nivel, porque a cada una de ellas se les llama Nuestra Madre. Cada una, en cuanto madre, es representativa y enlaza a sus hijos consigo misma. Quiere decir, $j a$

${ }^{29} \mathrm{El}$ nombre del sol divino según la costumbre es jwawtik. Se puede traducir 'nuestro padre', 'nuestro Dios'. Lo encontramos todavía en el giro ja smesa ja jwawtiki 'el halo del sol'. Se podría traducir 'la mesa de nuestro padre Dios'. Marcamos con letras versalitas la palabra costuMBRE, porque con esta palabra los tojolabales y otros pueblos mayas se refieren a su religión tradicional. La traducción con el término Dios es dudosa porque la palabra, de hecho, no parece existir.

${ }^{30} \mathrm{Se}$ trata de la Virgen en la cabecera municipal de Las Margaritas, Chiapas. El giro tojolabal lo podemos traducir 'Nuestra Madre Margarita' o 'Santa Margarita' o 'La Virgen Margarita'.

${ }^{31}$ Para muchos tojolabales, Jesucristo pertenece a la pluralidad de los padres que tenemos. jtatik corresponde también a la traducción 'Santo' con referencia a los 'Santos'. Jesucristo está, pues, integrado en la comunidad cósmica de consenso.

${ }^{32}$ Es el Santo de Zapaluta o Trinitaria a $16 \mathrm{~km}$ de Comitán por la carretera panamericana hacia el sur. Si se nos permite queremos dejar la traducción del nombre de este jtatik (el dos veces padre) a nuestro lector benevolente y su imaginación.

${ }^{33}$ Algunos van a decir que la complementación es sincretismo y, por ello, no auténticamente cristiano. Según sabemos, desde el momento de la "encarnación" el cristianismo se ha metido en este mundo y no hay cristianismo "puro". Los tojolabales, a 
jnantik walalupe, la madre morena de la piel de los autóctonos, madre de los indios discriminados, vencidos y explotados, es la madre que se manifiesta en la periferia de la sociedad fuera del centro de los conquistadores, gobernadores y pudientes. Tiene su morada donde los pobres.

Su hermana, ja jnantik lu'um, es la madre proveedora para que sus hijos tengan vida por los frutos de la tierra; por este hecho es la madre de la vida y la madre que nos da vida. Como Madre Tierra no puede ser propiedad de nadie porque madres no se venden ni se compran. A las madres se les respeta y se les sirve. Aquellos que la tratan de mercancía no la respetan ni le sirven, sino que la desprecian y la destruyen. ${ }^{34}$

La tercera de las hermanas, ja jnantik 'ixaw (luz pequeña en el firmamento, no se hace grande, mini stoyo $\left.s b^{\prime} a j\right)^{35}$ integra a sus hijos en la red de dimensión cósmica así como sus hermanas los incorporan a la misma red de dimensiones terrestre, social, cultural y religiosa.

La jnantik margarita, representante maternal en la región de los tojolabales, tiene su día particular cuando convoca al pueblo tojolabal que le presenta las flores con alegría y música todo en expresión del respeto que los tojolabales le manifiestan a esta Madre de ellos.

El "Dios" masculino, en cambio, es el jwawtik, 'nuestro papá, representado por el sol $j a k^{\prime} a k^{\prime} u$ ' $i$ cuyo nombre religioso es precisamente ja jwawtiki que podemos traducir "nuestro Dios-Padre". Repetimos que esta traducción es problemática, porque el término Dios lo hemos agregado nosotros, no está en la expresión tojolabal. La raíz waw indica varias cosas: puede referirse a alguien a quien queremos con mucho

nuestro juicio, no hacen otra cosa que inculturar el cristianismo en lugar de copiar la versión occidental importada.

${ }^{34}$ Aquí vemos, desde la perspectiva tojolabal, la relación íntima de la religión o costumbre con la política, representada por el artículo 27 constitucional. No se trata de ninguna interpretación forzada. La consideración de la tierra como propiedad y mercancía representa, desde la perspectiva tojolabal, una actitud de falta de respeto, por no decir, una religión ajena que desconoce conscientemente a Nuestra Madre Tierra. La ermita de la colonia Tabasco lleva la siguiente inscripción referente a las dos madres mencionadas. ja iglesya catolica mariya de guadalupe stz'akatal ja jnantik lu'umi ye'nani skuchuneja cha ye'ni wa smak'layotika. 'La iglesia católica María de Guadalupe. Gracias a Nuestra Madre Tierra. Ella nos ha cargado y también ella nos ha mantenido'.

${ }^{35}$ No se jacta a sí misma para aparentar mayor tamaño y más fuerza. Es decir, no es presumida. En este sentido, un relato tojolabal habla de la luna en un contexto parecido al del Popol Wuj; véase la edición de Albertina Saravia E., 1992: 102. 
cariño ${ }^{36} \mathrm{y}$, por lo general, de poca edad; también puede referirse a una persona profundamente respetada y, por lo general, de edad. ${ }^{37}$ En cuanto Padre de nosotros, representado por el sol, no está solo porque tiene su compañera Nuestra Madre Luna. Los dos, pues, son nuestros Padres cósmicos. ${ }^{38}$

Por el otro lado, una cruz en el camino también la podemos llamar jun jwawtik 'un nuestro papá'. Estamos ubicados, pues, en el contexto de una comunidad cósmica que nos rodea por todas partes. Por ende, nosotros, el conjunto de los seres humanos, no estamos en el centro ni lo representamos porque pertenecemos a una familia cósmica de muchos miembros diferentes. Una cruz en cuanto jwawtik representa a uno de la pluralidad de padres que tenemos en el cosmos. Como tal es del género masculino. Los palos arreglados en forma de cruz no son de género masculino en el sentido del género gramatical, sino que lo son porque participan en la comunidad cósmica en la cual no hay nada que no tenga corazón, es decir, que no tenga vida. Su modo es vida, es el de jwawtik. No es mujer ni asexual, sino del sexo de los varones y por eso tiene el nombre de jwawtik.

Los ejemplos (41) y (42) han ampliado nuestra concepción de la pluralidad de los padres o papás que están poblando el mundo tojolabal. Notamos que el género de los padres nuestros tiene dos formas de expresión: jwawtik y jtatik. Posiblemente el primero de los dos términos expresa mayor respeto porque la raíz waw suele señalar 'edad' y, en el contexto tojolabal, la edad merece mucho respeto.

1.7.2. Otra función sintáctica. Nos falta estudiar la estructura sintáctica de la indicación del género mediante nan o tat según los ejemplos a partir de (35). Los mismos indicadores del género no sólo se emplean para los representantes de la costUMBRE sino también para la de-

${ }^{36}$ Llamamos a un nene kala wawa que corresponde al 'papacito' del castellano.

${ }^{37}$ Puede expresar lo sagrado delante de lo cual nos inclinamos para expresar nuestro respeto. El 'santo, santo, santo' de Apocalipsis 4,8 se traduce we ' $n$ wawal we ' $n$ wawal we' $n$ wawal. Es el padre de los hombres a veces también llamado 'corazón del cielo'. El sol lo representa sin identificarse con él. Tanto el jwawtik en cuanto padre y sagrado como nuestras diferentes madres o jnantik no tienen, a nuestro juicio, rasgos del "mysterium tremendum" según lo explica Rudolf Otto, 1947: 12 ss.

${ }^{38}$ No queremos entrar en la polémica ideológica por el concepto cristiano del Padre Dios único. La tradición maya, como lo sabemos por el Popol Wuj y otras fuentes, no es monista ni monoteísta. Hay una pluralidad de Dioses, de Madres y Padres con quienes convivimos y que nos acompañan. Por eso afirmamos que la comunidad de consenso, tan representativa de los tojolabales, es de extensión cósmica. Si queremos apreciar 
signación del género de animales y de cosas según explicaremos más adelante. Todas estas expresiones son compuestos que tienen el carácter de nombres propios.

Ahora bien, nos limitamos a los ejemplos presentados y observamos que, a diferencia del ejemplo (34) y de los anteriores ejemplos, a partir del (35) los sustantivos que sirven de indicadores del género desempeñan la función de modificadores atributivos. Los compuestos pueden explicarse de esta manera como la vemos en el (38) que nos sirve de ejemplo: ja jnantik lu'um corresponde a 'nuestra Madre Tierra', 'la Tierra que es nuestra Madre', 'nuestra Tierra maternal'. Es decir, el sustantivo prefijado jnantik desempeña el papel de atributo de lu'um.

Otra explicación, sin embargo, puede ser más probable. Todos los ejemplos representan compuestos cuya construcción sigue caminos y reglas particulares. Veamos el ejemplos de jnantik lu'um. La Tierra lu'um y Nuestra Madre jnantik se identifican y, de este modo, el género de la Tierra se evidencia con toda claridad. De la misma manera podemos explicar todos los ejemplos siguientes a partir del (35). Es decir, se manifiesta el género de 'ixaw, k'ak'u, lu'um y de todos los jwawtik. No se tata de convenciones arbitrarias que asignan el género gramatical a las cosas, sino que 'la luna', 'el sol', 'la tierra' y 'las cruces en el camino viven', tienen corazón y "género" o "sexo" como los demás vivientes. Como tales están poblando el cosmos que estamos compartiendo con todos ellos.

Los ejemplos de 'la luna, el sol, la tierra y las cruces' nos enseñan otra cosa. Desde la perspectiva occidental o moderna los cuatro ejemplos representan "cosas inanimadas". En la mayoría de los idiomas indoeuropeos tienen género que, hoy día, puede explicarse por el género gramatical. De hecho, en los ejemplos mencionados, el género empleado se explica por tradiciones muy antiguas, conservadas en las culturas occidentales. La investigación histórico-lingüística puede explicar las raíces profundas del género de las cosas cuyo género hoy día se llama "gramatical". En el contexto maya-tojolabal, a nuestro juicio, el género de las madres y padres cósmicos es una de las manifestaciones de que todas las "cosas" tienen corazón, por ello viven y como tales son de género femenino o masculino; tal vez mejor dicho, son mujeres u hombres.

y respetar esta y otras clases del pluralismo, debemos superar el prejuicio ideológico que nos dice que la reducción de todas las cosas a una sola fuera algo superior, no importa en qué rama del saber, creer o vivir. 


\section{El género de animales y cosas}

\subsection{El género señalado}

Comencemos con una sola clase de animales para señalar cómo se le asigna principalmente el género masculino.

(1) mut 'gallina, gallo'

(1a) kerem mut 'gallo' (joven aún, no sirve de semental)

(1b) snan mut 'gallina'

(1c) stat mut 'gallo' (gallo papá o gallo macho de edad; sirve de semental).

(1d) swaw mut 'gallo' (también sirve de semental)

(1e) xinuk mut 'gallo' (de cualquier edad)

(1f) ja tan mut 'el gallo ese' (el adjetivo tan expresa desprecio, ${ }^{39}$ se usa exclusivamente con el género masculino)

A diferencia de los ejemplos (1) al (9) del primer apartado, todos los indicadores del género de mut en este subapartado preceden al sustantivo. Dicho de otro modo, se habla principalmente de mut que recibe modificaciones de distintas clases: kerem, xinuk, etc. Es decir, los sustantivos modificadores desempeñan la función sintáctica de atributos, como ya lo vimos en el apartado $1 .{ }^{40}$ Aquí se habla de mut, los ejemplos (26) y siguientes del primer apartado hablaron de winik, 'ixuk, etc. Son esta clase de sustantivos que reciben determinadas modificaciones. Vamos a mostrar el paralelismo.

(2) yal winik 'hombrecito'

(2a) yal ${ }^{41}$ mut 'pollito'

${ }^{39}$ Sobre otros significados, véase 2.2 .

${ }^{40}$ Véase la construcción correspondiente en 1.6.

${ }^{41}$ yal es ambiguo. Se puede referir a 'hijo' o 'hija' de una mujer o hembra y puede expresar el diminutivo de la palabra que le sigue. Por ejemplo, ja yal winik ja nanali quiere decir 'el hijo de la mamá'. yal winik a solas puede significar 'hombrecito', y yal mut es el 'pollito' sin aclarar el sexo. De todos modos, queremos subrayar que en ambos ejemplos se habla o bien de winik o bien de mut. Los dos reciben distintas clases de modificaciones por los atributos que les preceden. La mencionada ambigüedad de yal se explica de la manera siguiente. Los hijos de una mujer son, por supuesto, pequeños. De 'al se deriva el verbo 'alini que podemos traducir "producir", es decir, así como la milpa produce. Estos productos son pequeños desde la perspectiva de la productora. 
(3) 'alatz ${ }^{42}$ winik 'nene'

(3a) kerem mut 'gallito'

(3b) xinuk mut 'gallo'

(3c) xinuk kristyano 'varón'

(4) tan winik 'hombre ese'

(4a) tan mut 'gallo ese'

Los ejemplos (2), (3), (3c) y (4) hablan de winik o de personas y los modifican de distintas maneras por los atributos correspondientes. Las variantes (2a) (3a y b) (4a), en cambio, hablan de mut y también lo modifican de las mismas maneras. En todos los ejemplos no se cambia la estructura sintáctica. Observamos que el modificador 'alatz se emplea sólo para personas.

Los ejemplos de snan mut, stat mut y swaw mut del grupo (1) exigen una explicación adicional. No sólo indican el género, sino que, al hacerlo, señalan a la vez la función reproductora de cada uno. Los modificadores llevan el prefijo agencial $s$ - que nos indica que se trata de mamás o papás del género mut. La referencia no es a los papás del mut en particular sino a los papás de mut en general. Por ello, se dice también

(1g) swaw wakax 'toro'

(1h) snan $t z$ ' $i$ ' 'perra'

\subsection{El ejemplo de $\tan$}

Nos falta analizar el adjetivo tan, cuyo significado suele expresar desprecio, sobre todo, con respecto a personas cuyo comportamiento no corresponde a las exigencias de la comunidad o, según el contexto, de otras instancias aceptadas por la sociedad tojolabal. El adjetivo me' $n$ hace las veces del adjetivo correspondiente para el género femenino. Lo explicaremos en el subapartado siguiente. Ejemplos:

(5) ja tan 'ajwalali 'el patrón ese'

(5a) ja tan lo'lanumi 'el vil engañador'

(5b) ja tan 'elk'anumi 'el ladrón desdeñable'

Los tres ejemplos hacen referencia a personas cuya conducta no se conforma con la vida comunitaria. Es decir, la vida de los 'ajwalal, lo'lanum y 'elk' anum se considera incompatible con las comunidades.

${ }^{42}$ Recordamos que 'alatz quiere decir 'lactante, recién nacido'. 
Si se dan casos de comportamientos de esta clase de gente en el contexto comunidad, ésta se ve llamada para que corrija a los infractores de las reglas ${ }^{43}$ de la vida comunitaria. Dicho de otro modo, el desprecio expresado por las palabras tan y $m e$ ' $n$ no justifica la falta de respeto hacia personas cuya conducta corresponde a las costumbres vigentes de la comunidad. Al desprecio injustificado se le considera "mal hablado" que sí es digno de represión. Un ejemplo sería agregar el adjetivo tan al nombre de una persona respetada.

La expresión tan también tiene la connotación de 'muy macho', 'vil', 'abyecto', 'astuto' o algo por estilo según el gusto y la región de procedencia del lector. En las traducciones de los ejemplos tratamos de expresar los significados variados, que se podrían multiplicar. Es importante señalar que el término puede tener otras acepciones que no señalan conductas reprensibles.

Un relato de la tradición tojolabal nos ayuda a entender mejor el significado amplio del adjetivo. El cuento nos habla de ja tan santo tomasi, es decir, Santo Tomás, patrón de Oxchuc, que se peleó con San Bartolo, santo patrón de Venustiano Carranza. ${ }^{44} \mathrm{El}$ primero salió vencedor a pesar de su pobreza que contrasta con la riqueza de San Bartolo. Parece que por esta razón se le asigna el modificador tan. El narrador no quiere expresar desprecio sino admiración, porque, como dirían los comitecos, Santo Tomás es muy "chingón". Se mantiene, pues, la referencia a una persona de sexo masculino pero se modifica el sentido negativo.

Ésta no es la única excepción del adjetivo. Los ejemplos siguientes nos muestran otras posibilidades del adjetivo tan, que indica el género y otras cosas.

(6) ja tantik ton 'las piedras (esas) $)^{45}$

(6a) ja tantik witz 'los cerros tremendos'

${ }^{43}$ Por supuesto no se trata de reglas escritas sino de costumbres aceptadas por todos.

44 Oxchuc y Venustiano Carranza son cabeceras municipales de Chiapas con sus santos patrones respectivos. En tojolabal, Venustiano Carranza se llama san bartolo. Es decir, tiene el mismo nombre que el santo patrón del lugar. La palabra Bartolo es la forma local o regional de Bartolomé.

${ }^{45}$ tantik en todos estos ejemplos del grupo (6) no expresa necesariamente desprecio. La referencia a Santo Tomás nos indicó otras posibilidades. Las traducciones, pues, no son más que aproximaciones. La referencia puede ser a piedras descomunales por el peso, el tamaño, el color, etc. Los lectores pueden buscar traducciones para los ejemplos (5a), (5b) y (5c). 
(6b) ja tantik tak' in 'el pinche dinero'

(6c) ja tantik te 46 'esos árboles'

Ninguno de los ejemplos hace referencia a personas o animales que, por naturaleza, se distinguen por el género. Surge la pregunta si, tal vez, existe el género gramatical en tojolabal. Los ejemplos parecen confirmar la idea. Antes de aceptarla tenemos que escuchar la opinión de los tojolabales.

Los giros de los ejemplos se oyen sólo en algunas colonias. ${ }^{47}$ Por ello, nos parece que se trata de regionalismos no bien aceptados por la mayoría de la población. Observamos, además, que siempre se usa la forma del plural. ${ }^{48}$ Algunos hermanos tojolabales explican las expresiones en el sentido de que en cada caso se trata de 'muchas cosas feas y despreciables'. La referencia a 'muchas cosas' se explica por el plural tantik. La calificación de 'fealdad', en cambio, se debe al desprecio que el adjetivo suele expresar.

La referencia de tan, tantik al género o sexo masculino hace surgir otra posibilidad de interpretación. Nos referimos al hecho de que, para los tojolabales, todas las cosas tienen corazón, es decir, son vivientes. Queremos indicar una probabilidad de interpretar estos giros regionales. Los ton, witz, tak'in, etc., son hermanos varones, compañeros de la comunidad cósmica a la cual pertenecemos todos nosotros. No podemos afirmar esta clase de explicación con seguridad. Por el momento nos parece una probabilidad fundada en la cosmovisión tojolabal.

\subsection{El género señalado de hembras y machos}

Ejemplos del género masculino:

(7) wakax 'ganado bovino' (de cualquier sexo)

(7a) kerem wakax 'toro'

(7b) stat wakax 'toro'

(7c) swaw wakax 'toro'

(7d) yal swaw wakax 'novillo'

(7e) xinuk wakax 'toro'

(7f) ja tantik wakax 'los toros (esos)'

${ }^{46}$ Vocabulario: ton 'piedra'; witz 'cerro'; tak' in 'metal', 'dinero, ?; te ' 'árbol, madera'.

${ }^{47}$ Por ejemplo en la colonia Gabino Vásquez, municipio de Las Margaritas, y comunidades vecinas, pero también en los ejidos de la selva, Guadalupe los Altos y San José Esperanza del mismo municipio. El uso regional en colonias tan apartadas se explica fácilmente, porque mucha gente de Gabino Vásquez pobló San José Esperanza.

48 Véase Carlos Lenkersdorf, 1994: 104-107, sobre el tema del plural. 
Las expresiones no exigen ninguna explicación porque los conocemos por los ejemplos (1) al (4) de este apartado con referencia a mut.

Ejemplos del género femenino:

(8) mut 'gallina, gallo'

(8a) yak'ixil mut 'gallina primeriza'

(8b) snan mut 'gallina'

(8c) xujxep mut 'gallina'

(8d) che 'el mut 'clueca'

(8e) ja me 'ntik mut 'las gallinas (esas)'

Expliquemos brevemente las expresiones usadas. yak'ixil se deriva de 'ak'ix 'muchacha'. ${ }^{49}$ La gallina caracterizada de esta manera es primeriza. La palabra xujxep, en cambio, quiere decir 'matriz'. Al llamar un mut de esta manera, se hace hincapié en su cualidad de gallina. che 'el mut es la gallina frígida. ${ }^{50}$ me $n t i k$, finalmente, es el plural de $m e$ ' $n$, la forma que se refiere siempre al género femenino y cuyo significado corresponde al adjetivo tan. Semánticamente suele señalar el desprecio, pero podemos observar las misma excepciones que notaremos con respecto al uso de tan.

Con respecto a la estructura sintáctica no hay diferencia alguna entre la construcción de expresiones referidas a hembras o machos. También encontramos el "regionalismo" de que algunas cosas se modifican por el adjetivo me $n$. Se dice en las mismas comunidades ya mencionadas en el contexto de (6):

(8) ja me 'ntik mes 'las escobas (esas)'

(8a) ja me 'ntik sek' 'los (pinches) cajetes'51

En resumidas cuentas, en tojolabal se indica el género natural de varias maneras. Está implícito en algunos sustantivos. Otros, para marcar el género, requieren indicadores particulares que suelen desempeñar la función sintáctica de atributos. En algunos casos el género indicado no es el esperado desde la perspectiva occidental o indoeuropea. Se señala el género de los progenitores y no el de los hijos. Esta diferen-

49 En cuanto a la forma yak'ixil, véase Carlos Lenkersdorf, 1994: 100-103.

${ }^{50}$ che 'e corresponde a 'frío, fría'. Por ejemplo, jel ja che' $e$ quiere decir 'hace mucho frío'.

51 'Cajete' es comiteco y corresponde a 'cazuelita' (de barro) en el dialecto del Distrito Federal. 
cia representativa entre el tojolabal y el castellano la tendremos que estudiar más en el apartado siguiente. Hay, finalmente, algunos giros regionales que parecen señalar el género gramatical de algunas cosas, pero los tojolabales no suelen aceptar esta explicación. Hicimos la sugerencia de que estos casos se explican por el hecho de que todas las cosas tienen corazón o vida y, por ello, tienen género.

\section{Otros aspectos de yal y yumin}

Con respecto a ambos géneros hay giros que, según sabemos, no tienen equivalente en castellano u otros idiomas indoeuropeos. Repetimos lo dicho con anterioridad. Al hablar de hijos, siempre se señala el género de los padres. El de los hijos resulta secundario. Por eso dijimos en 1.4.

- unin corresponde a hijo o hija, pero sólo puede serlo de un papá o varón. Por ello, debe llevar el prefijo agencial. Por ejemplo, kunin 'mi hijo, mi hija'.

- al corresponde a 'hijo' o 'hija', pero sólo puede serlo de una mamá o mujer. Por ello, también debe llevar el prefijo agencial. Por ejemplo, $k a l$ 'mi hijo, mi hija'.

No se indica el género de los hijos, pero sí de los papás, aunque estén ausentes o hayan muerto. En tojolabal nadie puede ser 'hijo' o 'hija' a secas. Siempre somos 'su hija' o 'su hijo de una mamá o de un papá'. Por eso, -unin y -al deben o bien llevar el prefijo agencial o bien ser modificados por el adjetivo agencial - ala ${ }^{52}$ De esta manera no se subraya solamente la red de relaciones a la cual todos nosotros pertenecemos, sino también el género de nuestra procedencia, de madre o padre. ${ }^{53} \mathrm{La}$ lengua tojolabal no nos permite ser hijas o hijos sin mencionar que lo somos de una mamá o de un papá y, por eso, a fuerza debemos indicar el género de uno de nuestros padres. ${ }^{54}$

Pertenecemos a una red de relaciones que requiere explicación y que nos hace ver con más claridad la diferencia entre el tojolabal e idiomas

52 Por ejemplo, kunin o kala 'unin 'mi hija' o 'mi hijo' al hablar un hombre.

${ }^{53}$ Es decir, -nan o -tat que, morfológicamente, se distinguen por raíces diferentes.

${ }^{54}$ Según la cosmovisión y lengua tojolabales, no se habla de hijas e hijos a secas. Siempre lo somos de mamás o papás y siempre se indica esta relación. No se trata de una falta de abstracción en el idioma mayense sino de la necesidad de señalar nuestra inserción en una "comunidad" muy amplia que nos toca explicar en seguida. 
indoeuropeos. Sabemos que todos somos hijos y no importa la cultura a la cual pertenecemos. Este hecho lo afirmamos en cualquier idioma. $\mathrm{Si}$ lo entendemos en serio, nunca, pues, somos la primera generación. Siempre somos de segunda para que no perdamos la humildad. El tojolabal, sin embargo, quiere decir más al afirmar que siempre 'somos sus hijos'. Es decir, 'hijos de una mamá y de una papá' determinados. No solamente los prefijos agenciales nos integran en la red de relaciones, sino que siempre formamos parte de la red en conjunto con nuestra mamá y nuestro papá. La sola referencia al hecho de ser hija o hijo implica, por necesidad lingüística, la referencia a nuestros papás, vivos o muertos. Desde la perspectiva tojolabal nunca jamás estamos tan solos como a veces nos lo imaginamos.

Ahora bien, podemos decir

(1) yuntikilotikon ja jnan jtatikoni. ${ }^{55}$ 'Hijos (somos) de nuestros padres (no de los tuyos)'.

Este sintagma se refiere a los dos padres nuestros. Éstos, en tojolabal, señalan siempre los dos géneros constitutivos de la maternidad y paternidad. El género de los hijos, en cambio, todavía no se aclara, porque yuntikilotik pueden ser 'hijas' o 'hijos'. Por ende, la mención del género de los papás tiene precedencia sobre la de los hijos. Si preguntamos, ¿por qué será?, debemos enfocar el problema de otra manera. No es el género el que tiene prioridad, sino que los papás la tienen. La razón puede ser que gracias al acto procreador de ellos formemos parte de la red cósmica, gracias a ellos somos 'sus hijos' y, como tales, formamos parte de una comunidad muy extensa. Dicho de otro modo, la estructura de estas y otras expresiones idiomáticas es tal que siempre se señala la interrelación a la cual pertenecemos. Ésta tiene más importancia que la indicación del género.

En cuanto al género de los papás, éste se menciona con toda exactitud posible y con más claridad que en castellano. La razón es que el tojolabal no se olvida de la mamá al hablar de sus padres, sino que habla de ja jnan jtatiki. Quiere decir, 'nuestra mamá y nuestro papá' forman lo que en castellano se llama 'nuestros padres' o 'nuestros papás'. En el plural yuntikilotik ${ }^{56}$ parece que ya no se habla de yal o 'hijos de la mamá'. No es así. La mamá sigue presente en la expresión ja jnan jtatikoni. Somos, pues, hijas o hijos de mamá y papá.

55 Más adelante explicaremos el giro particular jnan jtatikon.

${ }^{56}$ En cuanto a la forma yuntikilotik, véase Carlos Lenkersdorf, 1994: 101. 
El caso de -al es más complejo. Si se refiere a los hijos de la mamá, la problemática es la misma que señalamos con respecto a -unin. Es decir, siempre presupone a la mamá sin señalar el género de los hijos, a no ser que se agregue una palabra adicional.

Por ejemplo, se dice:

(2) yuninon ja wakumpare ' $i$. 'Soy hija de tu compadre'.

(3) yalon ja wakumare' $i$. 'Soy hija de tu comadre'.

Notamos que siempre se usa el artículo para señalar a las personas que son los papás. En este sentido no hay diferencia sintáctica con respecto al uso de -unin o de -al.

Sin artículo, en cambio, la referencia no suele ser a los papás, sino que se puede señalar la procedencia de alguien o algo pero también otra cosa. Por ejemplo,

(4) ja ' yunin kawu'a. '¡Cómo eres entrometido!'57

Ahora bien, - $a l$ se usa frecuentemente y tiene varios significados, de ahí lo complejo de la palabra. Se dice, por ejemplo, yal loj. Notamos que no se usa el artículo para determinar la palabra loj. Por ende, éste no representa a la mamá. loj se refiere a un 'gemelo' y yal expresa cariño y como tal sirve de diminutivo. Si llamamos a alguien yal loj, le comunicamos nuestro cariño al llamarlo algo como igemelito! No se indica ninguna procedencia de nadie ni de nada. Dicho de otro modo, la palabra yal es ambigua. A veces no se sabe si se habla de hijos o de otra cosa. Vamos a mostrar las razones de esta afirmación.

A veces se borra el límite entre yal diminutivo/expresión de cariño, yal 'hija'o 'hijo de una mamá' y yal 'procedente de algo'. Vamos a contrastar los varios significados en el ejemplo (5) y sus derivados:

(5) diminutivo; procedente de hija/hijo de mamá; dudoso

(5a) yal ch' in 'pequeñito'

(5b) yal chab' 'larvas de abejas'

(5c) yal chan 'pájaro'

(5d) yal 'untik 'niñito'

${ }^{57} \mathrm{La}$ expresión es un regaño fuerte. yunin kawu se podría traducir 'hijo de caballo', pero no es correcto, porque no se dice yunina ja kawuji 'eres hijo del caballo'. yunin sí señala procedencia que, en este caso, es el caballo. Preferimos abstenernos de ofrecer una traduccion por una promesa hecha a los tojolabales de no enseñar "malas palabras". 
(5e) yal 'ako 'larvas de avispas'

(5f) yal kawu 'caballito' (en la feria)

(5g) yal nux 'chiquitín'

(5h) soj yal 'polluelo'

(5i) yal mut 'pollo'

Expliquemos brevemente algunas palabras y expresiones.

PRIMER GRUPO: INTENSIFICACIÓN POR YAL; POR ELLO, DIMINUTIVO:

(5a) ch'in 'pequeño, pequeña'; yal ch'in 'pequeñito'

(5d) untik 'niña, niño'; yal 'untik 'nena, niñito'

(5g) nux 'chaparro, chaparra'; yal nux 'chaparrito'

SEGUNDO GRUPO: PROCEDENTE DE, HIJA O HIJO DE UNA MUJER:

(5b) chab' 'abeja, miel', yal chab' 'larvas de abejas'

(5e) 'ako 'panal de avispas' yal 'ako 'larvas de avispas'

(5h) soj 'nido'. Se trata de los "hijos" de la gallina que están en el nido. soj modifica los yal, cuya mamá no se menciona. No se puede invertir el compuesto, porque significaría 'hijos del nido'.

(5i) yal mut se refiere a 'pollo' igual que mut. No es el 'polluelo' (véase 5h). Posiblemente es un pollo chiquito o sencillamente el mut llamado yal porque es pequeño de por sí o porque se le quiere expresar el cariño como, por ejemplo, en yal loj. En este caso yal mut pertenece también al primer grupo.

A veces las expresiones se vuelven más difíciles aún para encontrar una explicación. Nos referimos a este ejemplo:

(5c) yal chan 'pájaro'

El nombre chan se refiere a 'serpiente'. ¿Qué, pues, quiere decir yal chan? Puede ser (a) una 'culebrilla', (b) 'aquello que procede de una serpiente' o (c) un compuesto según una regla, particular de los componentes. ${ }^{58}$ Refiriéndose a 'pájaro' es posible que la explicación se da por (c), pero no sabemos si por alguna razón los tojolabales deri-

${ }^{58} \mathrm{El}$ tema de los compuestos lo enfocaremos en otra publicación que tenemos en preparación. 
van los yal chan de los chan. En este caso hay que optar por la posibilidad (b). ${ }^{59}$

En otros casos el asunto parece más claro. He aquí algunos ejemplos:

(6) yal k'ab' 'dedo' (criatura de la mano o del brazo)

(7) yal kok 'dedo del pie' (criatura del pie o de la pierna) ${ }^{60}$

(8) yal ja' 'gusano' (criatura del agua)

Vimos que yal señala el género de la procedencia de ser hijo o hija de una madre o productora. Por ende, $k^{\prime} a b^{\prime}, k o k^{61}$ y $j a^{\prime}$ pueden desempeñar el papel correspondiente. Nuestra lógica, sin embargo, no atina bien, como el ejemplo siguiente lo mostrará:

(9) snan yal k'ab' 'dedo gordo' (es decir, mamá de las criaturas de la mano)

Si seguimos la misma lógica, yal tiene dos mamás o dos productoras: snan y $k^{\prime} a b^{\prime}$. De esta manera, evidentemente, no podemos resolver el problema. Éste tal vez encuentra su resolución conforme a la sugerencia siguiente. Es decir, yal k'ab' representa una clase de cosas o un compuesto cuya snan o 'mamá' es el dedo gordo. La snan es una expresión metafórica como en (10) que sigue. Es decir, $k$ 'ab', etc., representa algo como criadora o productora. En este sentido se usa también con respecto a cosas. Se habla del

(10) snan wajab'al 'tambor mayor'

(11) yal wajab'al 'tambor pequeño'

Una explicación metafórica en el sentido de diminutivo sí existe también con respecto a yal, como lo vimos en (5a), (5d) y (5g). En (8), sin embargo, la referencia parece ser la de hijos de la 'mamá agua'. Es decir, semánticamente, snan, yal y las 'mamás' de yal no deben interpretarse con rigor a no ser que digamos que distintas familias se interrelacionan. No queremos forzar el asunto.

Por el otro lado, nos parece posible que los sustantivos mencionados señalan el género de palabras determinadas. Si nuestra interpretación es

${ }^{59}$ Faltan muchos conocimientos con respecto a la taxonomía tojolabal.

${ }^{60}$ En los ejemplos (6) y (7) yal puede representar también el diminutivo.

${ }^{61}$ kok lleva prefijo. yal kok, pues, se refiere al 'dedo de mi pie'. 
correcta, tenemos que conceder que la vida se encuentra no sólo en el "mundo" orgánico sino también en el inorgánico.

\section{Mujeres y hombres}

En el apartado anterior notamos que en español hablamos de 'nuestros papás' o 'padres' sin mencionar a nuestra mamá. En tojolabal, en cambio, al referirnos a nuestros progenitores los llamamos ja jnan jtatiki 'nuestros ${ }^{62}$ mamá y papá. A diferencia del castellano debemos mencionar a nuestra mamá que, además, precede al papá. El tojolabal hace hincapié en la relación social al mencionar tanto a la mujer como al hombre.

Nuevamente notamos otra perspectiva de la cosmovisión tojolabal que nos parece característica. Los papás representan, desde el principio, una relación social que se debe señalar y en la cual la mujer desempeña un papel importante, de manera tal que la mencionamos en el primer lugar. En español la mamá está implícita al hablar de nuestros padres. La diferencia de los rasgos típicos sigue manteniéndose en los dos idiomas. Veamos algunos ejemplos seguidos de la traducción correspondiente. Entre paréntesis agregamos los giros acostumbrados en español.

(1) 'ixuk winik ${ }^{63}$ "mujeres y hombres" (hombres y mujeres)

(2) ja jme 'xep jtatawelotiki "nuestros abuelas y abuelos" (nuestros abuelos)

(3) che 'um tatam "esposa y esposo" (esposos)

(4) 'ak'ix kerem "muchachas y muchachos"

No es necesario agregar más ejemplos. Todos nos señalan la misma estructura ya explicada. Es decir, las mujeres siempre tienen prioridad sobre los varones. Algunos pueden pensar que es por pura casualidad que, en tojolabal, se mencione a las mujeres primero. El mismo argumento pueden aplicar al español y otros idiomas relacionados que invierten el orden al hablar primero de los hombres y no de las mujeres. Nos acordamos que se dice: hombres y mujeres, muchachos y muchachas. ${ }^{64}$ En otros giros no se menciona a las mujeres porque se les con-

\footnotetext{
${ }^{62}$ En tojolabal no se indica, por supuesto, el género como se hace en nuestras o nuestros.

${ }^{63}$ La referencia al singular o plural no importa. Véase Carlos Lenkersdorf, 1994: 104.

${ }^{64}$ Véase también Men and women, Männer und Frauen, etcétera.
} 
sidera implícitas, como lo indicamos al principio de este apartado. Otras expresiones nos demuestran que las construcciones no son productos de casualidad ni de arbitrariedad. He aquí los ejemplos:

(5) señoras y señores

(5a) damas y caballeros

Estos ejemplos pertenecen al lenguaje de cortesía, es decir, el habla de la corte de los "nobles" cuando los hombres de categoría o de la vida cortesana montaban caballos. A sus cónyuges o a las mujeres de elevada posición social se les llamaba damas porque se les consideraba dominae es decir señoras, personas en cuyas manos está el mando. Los hombres correspondientes eran, por supuesto señores, es decir domini, los que están dominando. Esta clase de expresiones las seguimos usando hasta el día de hoy, y también se emplean en otros idiomas indoeuropeos. Nos acordamos de los giros ladies and gentlemen, mesdames et messieurs, etc. Es el lenguaje de la "urbanidad" que quiere poner a las mujeres en primer lugar y tratarlas con nombres especiales. Si la conducta corresponde al lenguaje utilizado no nos toca decir aquí.

Ahora bien, en tojolabal se conoce esta clase de giros de la "urbanidad" en castellano pero, al traducirla al idioma mayense nos espera una sorpresa.

Nos referimos a un trabajo realizado por encargo de muchas comunidades tojolabales: la traducción del Nuevo Testamento en griego a su lengua. La realización del proyecto nos ocupaba durante cinco años con 70 traductores, delegados de las comunidades. En el curso del trabajo se tuvo que traducir un texto que habla de esta clase de mujeres y sus esposos, es decir, "señoras y sus hombres", como dice el texto griego. Los tojolabales tradujeron ja jnal xinani. ${ }^{65}$ Quiere decir, señores y señoras. La traducción me sorprendió y les pregunté a los traductores si no se debe mencionar primero a las señoras. Sin vacilar me respondieron que entre ellos "a las mujeres no se les da prioridad".

La respuesta nos explica varias cosas. Conscientemente los tojolabales mencionan a las mujeres en primer lugar en la clase de giros citados que hablan de los dos sexos. ${ }^{66}$ No se trata de palabras vacías ni de giros arbitrarios o accidentales. Con el orden de palabras señalado quieren expresar la precedencia que están otorgando a las mujeres. Saben también que su manera de hablar corresponde a su manera de vi-

${ }^{65}$ Véase ja yajk'achil sju'unil ja dyosi, vol. 1, ja ya'teli 17,12.

${ }^{66}$ Véanse ejemplos (1) al (4). 
vir y comportarse, correspondencia que no han observado entre los no indígenas. En la sociedad dominante hay otros modos de comportamiento. La misma sociedad, además, no entiende a los tojolabales. Existen muchos malentendidos por ignorancia, falta de interés y razones por el estilo. Por ello, tampoco entienden las relaciones sociales de los tojolabales, sea con respecto a las mujeres o con otros.

A pesar de la crítica tojolabal de los "señores y señoras", tenemos que darnos cuenta de que su idioma tiene vocablos que corresponden a damas, caballeros, señores, etc. Son los términos que sólo se usan con referencia a los no tojolabales, no indios, no pobres, etc. Esa "gente de categoría" representa, desde la perspectiva tojolabal, a una clase socioeconómica determinada. Son los patrones, opresores, etc., de los cuales tienen una opinión particular que tal vez se formó por la experiencia del "baldío". ${ }^{67}$ Saben que esta clase de gente se porta de manera diferente de los modales tojolabales, sobre todo con referencia a las mujeres. En las fincas han visto los comportamientos de patronas y patrones. Han vivenciado en carne y hueso la vida bajo el mando de los finqueros y sus representantes. Mantienen la memoria viva en sus comunidades y enseñan al respecto a las generaciones jóvenes de hoy día para que no se olviden de esas experiencias amargas.

En tercer lugar, con base en esta historia vivida llegan al enjuiciamiento de la sociedad dominante y su lengua. Sus palabras, por bonitas y "urbanas" que suenen no van de acuerdo con la realidad vivida y, por ello, los hombres no respetan a las mujeres.

Señalamos que esta clase de giros expresan "urbanidad", cortesía y cosas por el estilo. Los tojolabales, en cambio, no son urbanos, es decir, no son de las urbes, de las ciudades, sino que son campesinos. Viven con la tierra, su respetada madre, con los animales y las plantas y toda la comunidad cósmica. Dentro de esta comunidad se vive y se expresa el respeto y la precedencia dados a las mujeres que jamás son damas, ni señoras, sino mujeres, madres y hermanas. Para ellos, las realidades lingüística y extralingüística tienen que concordar. Desde la perspectiva tojolabal-campesina, la sociedad urbana, que se considera a sí misma culta y refinada, no manifiesta dicha concordancia. Para los tojolabales la lengua, pues, no se restringe al campo limitado de las palabras, sino que éstas tienen que ir de acuerdo con los hechos referidos.

Otra experiencia en el curso de la traducción del Nuevo Testamento confirma nuestras afirmaciones y les da mayor claridad. Uno de los tex-

${ }^{67}$ Véase Antonio Gómez Hernández y Mario Humberto Ruz, 1992: passim. 
tos griegos por traducir habla de cuentos de viejas. ${ }^{68}$ Los tojolabales se sintieron molestos por la expresión. Se preguntaron, ¿cómo es posible que en la Biblia se hable con desprecio de personas de edad y de mujeres. Nosotros, en nuestras comunidades, mantenemos con firmeza el respeto a las personas ancianas. Lo expresamos en palabras y comportamiento. A las personas de edad se les llama 'ancianas' o 'ancianos' (me 'jun o tatjun) para manifestar el honor que se les debe.

Por las razones expuestas los traductores tomaron el acuerdo de no traducir el giro, sino de buscar otra expresión que corresponda a su manera de vivir, de comportarse y de ver el mundo. Optaron por el giro: los cuentos que no sirven (ja lo 'il jumasa ' ja b'a mi xmakuni). ${ }^{69}$ Este testimonio nos enseña que, para los tojolabales, realidades lingüística y extralingüística deben ir en concordancia. El género no es sólo una categoría formal de la lengua sino que refleja realidades sociales, culturales y políticas. El autor del escrito neotestamentario representa una posición no aceptable de parte de los tojolabales. Es decir, el desprecio de otras personas - mujeres, gente de edad y los demás— ${ }^{70}$ infringe las "reglas" no escritas o las costumbres de la convivencia comunitaria; son obligaciones que, obviamente, tienen aspectos socioculturales y políticos.

Otra observación nos hace falta aún. Al usar géneros, las lenguas deben expresar preferencias. Uno de los géneros tiene que ubicarse en el primer lugar o en la posición de prioridad. Vemos que tanto el español como ei tojolabal han tomado las opciones correspondientes. En tojolabal se pone, conscientemente, a las mujeres en primer lugar. Los hispanohablantes toman la decisión opuesta. Con las opciones respectivas, tanto los tojolabales como los de habla castellana expresan valoraciones cuyas repercusiones socioculturales hemos indicado y que nos parecen evidentes. La diferencia observada entre los dos idiomas nos enseña, a nuestro juicio, que no se trata de cosas fortuitas sino de realidades de las cuales muchos hispanohablantes no son conscientes.

\subsection{Lengua inclusiva}

Iniciamos este trabajo con una pregunta que nos causó asombro. En español y otros idiomas relacionados se dice él, ella. En tojolabal, en cam-

${ }^{68}$ Véanse C. Lenkersdorf, coordinador, ja yajk'achil sju'unil ja dyosi, vol. 2, 1993: 245,1 timoteyo 4,7 .

${ }^{69} \mathrm{Ibidem}$, p. 10.

${ }^{70}$ Otra cosa es el desprecio de los que no respetan la vida comunitaria. Véase 2.2 . de este trabajo. 
bio, no existe esta diferenciación. Se dice simplemente ye ' $n$. No se señala si ye ' $n$ se refiere a ella o a él. Esta distinción no les importa a los tojolabales. Por lo general, el contexto la explica. Si no lo hace, no les inquieta ni les parece interesar. Nos da la impresión de que la indicación del género o sexo la consideran un asunto secundario porque hay otros que cuentan más en el habla tojolabal.

Antes de mostrarlos, nos parece recomendable y necesario reflexionar un poco sobre el significado de la mención del género en la tercera persona de los pronombres. Nos va a mostrar cosas que, a menudo, no se consideran ni tampoco se ven. La razón puede ser que los lingüistas se olvidaron del asunto o no quieren investigarlo por no tomarlo en serio. Sea la razón que fuera, la indicación del género es un hecho que, a nuestro juicio, el lingüista tiene la obligación de investigar.

Ahora bien, en español se indica el género no sólo en la tercera persona del singular de los pronombres, sino también en el plural. Se dice, nosotros, nosotras; vosotros, vosotras; ${ }^{71}$ ellos, ellas. El señalamiento, pues, debe considerarse cosa de importancia si se indica en casi todas las personas. Observamos, además, que el masculino siempre se ubica en el primer lugar, aunque, si seguimos el alfabeto, el orden debería ser a la inversa: nosotras, nosotros, etc. Pero no se hace así. El género masculino, los hombres, siempre preceden a las mujeres o al género femenino. En casi todos los adjetivos la situación es la misma: en el primer lugar está la referencia a los hombres o al género masculino. ¿Cuál es la razón? ¿Será porque la mayoría de los gramáticos desde Aristóteles y Nebrija fueron hombres? Ignoramos la respuesta y los teóricos de las lenguas ya no nos pueden informar el porqué de sus decisiones. Tal vez tampoco saben si las tomaron de modo consciente o no. El hecho es que el español y muchas otras lenguas indoeuropeas señalan el género en los lugares mencionados y que las gramáticas, los diccionarios y la enseñanza escolar siempre dan prioridad al género masculino.

Este hecho se suele aceptar sin detectar ningún problema. ¿Es justo y científico desproblematizar la primacía del género masculino? ¿No es inquietante la mención necesaria de él o ella si nos damos cuenta de que otras lenguas y culturas no lo hacen?

Con respecto al tojolabal sabemos que la situación es muy diferente. Notamos: la ausencia de la mención constante y necesaria del género, la primacía de las mujeres al hablar de los sexos y la conciencia de que el habla debe reflejar el respeto que se les debe a las mujeres y a las personas de edad, como a todos los demás representantes de la comu-

${ }^{71} \mathrm{El}$ usted, por supuesto, ya no hace referencia al género. 
nidad. Por ello, concluimos que el tojolabal es un idioma inclusivo. Es decir, a los géneros y sexos se les concede igual importancia. ${ }^{72}$

\subsection{Nosotros y nosotros}

Al enfocar el tojolabal no sólo notamos la ausencia de la problemática señalada, sino que hay otras particularidades idiomáticas, casi intraducibles, que caracterizan la lengua.

Por ejemplo, si una familia de habla española de cinco personas está reunida en la comida y los hijos le dicen a la mamá, "vamos a la milpa", la madre no sabe si ella también va o no. La frase castellana es equívoca. $\mathrm{La}$ ambigüedad no se da en tojolabal. Esta y otras lenguas mayenses distinguen dos formas de la primera persona del plural. No son diferencias de género, sino de dos conceptos del NOSOTROs. El uno incluye a la persona con quien hablamos y el otro la excluye. Por ello, los gramáticos hablan del inclusivo y exclusivo. En tojolabal las formas correspondientes son ke 'ntik y ke 'ntikon. ${ }^{73}$ Estas formas las encontramos no sólo con los pronombres, sino también con los sustantivos, adjetivos y verbos. Es un "arreglo" que penetra todo el idioma, toda el habla como uno de los rasgos característicos. Es decir, en lugar de diferenciar necesaria y constantemente los géneros, hay que distinguir con la misma necesidad las distintas formas del Nosotros. ¿Qué nos señala el hacer hincapié en el NOSOTROs?

En primer lugar tenemos que repetir que ke'ntik y ke'ntikon no son equivalentes de NOSOTROS o NOSOTRAs. Es decir, no indican el género. Pueden referirse a mujeres, hombres y todos los demás que forman parte del ke'ntik y ke'ntikon. Por ello, se excluye la opción de dar preferencia a uno de los dos géneros. Al hablar del Nosotros tenemos que entender que ke'ntik y ke'ntikon incluyen los dos géneros o sexos. El NosoTROs, pues, predomina sobre géneros o sexos.

Los términos ke'ntik y ke'ntikon se refieren, obviamente, a un grupo, el de Nosotros. Regresamos al ejemplo empleado. Los hijos, al decir a

${ }^{72}$ Esta observación, por supuesto, no excluye la posibilidad de que algunos hombres tojolabales golpean a sus esposas. Por todos lados encontramos "machistas". Por el otro lado, en el contexto de la sociedad hispanoparlante o indoeuropea hay hombres no machistas. Las excepciones confirman las reglas. Hacemos hincapié en esto para subrayar que no estamos generalizando sino que señalamos rasgos característicos que podemos observar en las estructuras de la las lenguas y en las realidades correspondientes nombradas.

${ }^{73}$ ke 'ntik corresponde a 'nosotros, nosotras' y ke 'ntikon lo hace también. 
la mamá, "vamos a la milpa" usan la forma de ke 'ntikon. Es decir, los hijos no esperan que la mamá les ayude. Dicho de otro modo, por RESPETO usan la forma del exclusivo. Le dicen a la mamá que no es necesario que ella gaste sus energías en el trabajo duro de la milpa. Los hijos se encargan de esta responsabilidad. El ke 'ntikon, pues, no excluye a la gente del grupo, sino que se reconoce una jerarquía dentro del mismo grupo. No se trata de nivelar a todos, porque el grupo representa, obviamente, una jerarquía social dentro de la cual cada uno tiene responsabilidades o tareas diferentes. ${ }^{74}$

Al hacer hincapié en el grupo, tanto las diferencias dentro del grupo jerárquico como la referencia al respeto, nos hace ver los primeros rasgos típicos del NOSOTROs. Por las afirmaciones hechas captamos con mayor profundidad el concepto. Representa, por decirlo así, el punto de partida de la vida tojolabal. Se trata de la comunidad en cuyo contexto los tojolabales nacen, se forman, viven y actúan. De ahí se explica la importancia del NOSOTROs.

Al contrastarlo con los géneros, indicados en español, vemos que la referencia es a la comunidad sin mencionar los géneros de los participantes. No se piensa en individuos, por ejemplo, yo, tú, él, ella; tampoco en la suma de ellos. Es el conjunto orgánico al cual el NOsOTROs se refiere y al cual el tojolabal se refiere constantemente.

Podemos decir que, en el contexto de idiomas de las sociedades dominantes, nos impresiona el hincapié que se hace en el yo o la persona individual. Se trata de contextos de solitarios, por no decir egocentristas, que conducen a la competencia de los yos, competencia en el comercio, en el sistema escolar, en el ambiente profesional, etc. Es la competitividad que se está alabando como señal de la modernización. Se dice y se propaga la idea de que las sociedades deben ser competitivas.

Para contrarrestar los efectos dañinos de la competitividad de los yos se habla de la relación yo-Tú. De todos modos, e independientemente de que se haga hincapié en el Yo o en la relación Yo-Tú, siempre se trata de individuos que no saben vivir en comunidad o que tienen que aprenderlo. Con respecto a él o ella se sabe que no se dan relaciones comunitarias en el nivel de Yo-ÉL/ELLA porque en este nivel no se da la igualdad de relaciones. Por ello, se habla de la relación yo-Tú.

Ahora bien, al escuchar una plática en tojolabal notaremos la predominancia del NOSOTROS, es decir del $(k e$ ' $n) t i k$ y (ke' $n) t i k o n$. El

${ }^{74} \mathrm{El}$ ejemplo no quiere ser más que esto. No hay que generalizarlo en el sentido de que a las mujeres no les tocan trabajos también pesados. 
punto de partida de ver la realidad (la cosmovisión), de nombrarla, de expresarla en palabras y de vivirla es la comunidad del Nosotros. Dicho de otro modo, los tojolabales siempre se conciben a sí mismos como partícipes de una comunidad que es de consenso y no del predominio de la mayoría. No buscan ser individualistas sino comuneros. No niegan las diferencias individuales. El ejemplo de los hijos que hablan con su mamá nos lo hace ver. Por ello, la comunidad es la condición de posibilidad para el desarrollo de cada individuo y, a la vez, el desafío que está retando a cada comunero. En el contexto tojolabal los individuos no pueden formarse a no ser que se porten como comuneros, porque la comunidad les hace posible desarrollarse.

Esperamos que la exposición nos haga comprender la razón de la importancia del Nosotros, representante de la comunidad cuyos inicios se dan en la comunidad local y que se extiende para incluir a los miembros del cosmos: "nuestra madre tierra", "nuestra madre luna", "nuestro padre sol", etc. Notemos que siempre se habla de "nuestra...nuestro..."

La amplitud del Nosotros nos enseña no sólo su importancia, sino también, a nuestro juicio, la diferencia de la importancia de los géneros. Éstos, por decirlo así, separan a los unos de los otros. Tienen que hacerlo porque tienen que hablar de mujeres y hombres, diferencia que exige establecer preferencias. El Nosotros, en cambio, requiere y establece comunidad.

En el contexto tojolabal, el género se puede indicar, pero en muchos casos no se hace, porque otros aspectos se consideran de mayor importancia. Lo notamos en la referencia a los progenitores que integran a los hijos en la comunidad que se hace presente y nos reta en el NOSOTROS que nos hermana social, política y culturalmente. La lengua nos hace captar la comunidad porque mediante el idioma nombramos las cosas que vemos y según las vemos.

\section{Personas y cosas}

Vamos a añadir un asunto más que está relacionado con el tema, sin referirse directamente a los géneros. Hay unas palabras que pueden desempeñar los papeles de adjetivos/pronombres indefinidos e interrogativos. Nos referimos a jasunk'a y machunk' $a^{75}$ y sus derivados. El primero suele referirse a cosas, el otro a personas. He aquí unos ejemplos.

\footnotetext{
${ }^{75}$ Véase Carlos Lenkersdorf, 1994: 204-207.
} 
(1) jasto junk'ila 'oj kale ${ }^{76}$. ¿QQué más diré?'

(2) jasunk'a b'a 'oj jk'ul sok ja 'elk'anumi. '¿Qué pues haré con el ladrón?'

(3) mi jasunk'ilukona. 'No soy nada'

(4) jasunk'a b'a ja' 'oj 'a'juk ki'tikoni. '¿Qué, pues, se nos dará?'

(5) machunk'ilon ja ke 'ni. '¿Quién soy yo?'

(6) mach' junuk'a 'oj yi ' kani ja ajastik ab'aji. '¿Quién recibirá las cosas tuyas?'

(7) machunk'a junuk ja ye 'nle 'i ja mas niwani. '¿Quién de ellos es el más grande?'

(8) machunk'a ja smuli. '¿De quién es el delito?'77

Los ejemplos nos enseñan que jas y sus derivados se refieren a cosas $^{78}$ y mach' a personas. Podemos pensar en la jerarquía de animación mencionada en 1.2. Si ésta incluye lo no animado, no nos parece aceptable, porque, desde la perspectiva tojolabal, no hay nada que no tenga corazón, es decir, vida. Por el otro lado, seguramente hay diferencias o distintas clases de vida, digamos vida orgánica e inorgánica desde la perspectiva occidental. En el contexto tojolabal, tal vez, es más acertado hablar de cosas con corazón o vida y personas con corazón o vida. La razón de la afirmación es la siguiente. Como tojolabales platicamos con animales y plantas y también pedimos disculpas a los tenamastles o el fuego por haberlos maltratado. De esta manera manifestamos que, dentro de la cosmovisión tojolabal, estas cosas tienen vida, son animadas.

Dicho de otro modo, seguramente hay una jerarquía de todo lo que vive y la misma no es exclusiva. Por la participación de todas las cosas en la vida se explica también el hecho de que a algunas "cosas" se les asigna un género determinado como lo señalamos en 2.2 y 2.3 , pueden ser femeninas o masculinas. Por ende, no son neutras aunque son cosas. Esta conclusión, sin embargo, no se puede generalizar, porque otros tojolabales no están de acuerdo con que se le asigne uno de

\footnotetext{
${ }^{76}$ Vemos que la forma originaria es jas junk'a. La forma jasunk'a es una contracción.

${ }^{77}$ En cuanto a la estructura sintáctica de los ejemplos (1) al (8), véase Carlos Lenkersdorf, 1994: 204-207.

${ }^{78} \mathrm{Hay}$, sin embargo, el giro, jas winik o algo por el estilo. Quiere decir, '¿cuál hombre?' Es decir, en esta clase de construcciones jas no se refiere a cosas. No podemos afirmar, pues, que jas siempre se refiere a cosas.
} 
los dos géneros a las cosas. Por ello, se da la posibilidad de considerarlas cosas neutras o sin género pero sí con corazón o vida.

\section{Conclusión}

El trabajo nos ha señalado las particularidades del tojolabal, a menudo a diferencia del castellano, con respecto al uso del género. El tema nos ha exigido trascender los límites de la lengua y la estructura lingüística y meternos en el campo extralingüístico porque mediante las lenguas nombramos el mundo que vemos y lo hacemos según nuestra perspectiva, condicionada por la sociedad y cultura a la cual pertenecemos. Por ello, el tema "gramatical" del género ${ }^{79}$ nos ha conducido a explicar costumbres o comportamientos tojolabales que se derivan de su cosmovisión que, a su vez, forja estructuras lingüísticas. La vinculación de un tema lingüístico con la realidad extralingüística la enfocamos con respecto al género que nos ha servido de ejemplo. Seguramente no es el único porque las lenguas en su totalidad son los instrumentos que nos sirven en las culturas diferentes para nombrar el mundo que vemos, "formamos" y comprobamos según nuestras perspectivas. Por lo tanto, los estudios lingüísticos nos conducen a conocer las culturas desde adentro, que se nos manifiestan sin que la mayoría de los hablantes se den cuenta de todo lo que están revelando, porque implica la conducta, los valores, la ideología, preferencias sociopolíticas y tantas cosas más. Por ello, afirmamos que la investigación de las lenguas nos está retando para conocer tanto a la cultura nuestra como a las otras. Nos hace ver muchos aspectos que, por lo general, no queremos admitir y que nos hacen encarar realidades escondidas. ${ }^{80}$

$\mathrm{Al}$ exponer la temática del género nos dimos cuenta de la importancia de las perspectivas que forman el puente entre las lenguas y las cosmovisiones correspondientes. Nos hacen percibir aspectos del mundo muy diferentes. Surge la pregunta que no vamos a tratar ya en este trabajo: ¿las perspectivas diferentes nos hacen ver no sólo otros aspectos de la realidad sino otras realidades? La respuesta la buscaremos en el contexto de otro tema.

${ }^{79} \mathrm{Si}$ queremos podemos clasificarlo estrictamente lingüístico, separado del sistema de la realidad vivida. Pensamos que este enfoque no nos hace captar a fondo el tema del género.

${ }^{80}$ En nuestra conclusión afirmamos nuestro acuerdo con la posición de Sally McConnel-Ginet, 1990: 95 ss. 


\section{Bibliografia}

Alonso, Martín

1968 Gramática del español contemporáneeo, Ediciones Guadarrama, Madrid.

BRODY, Jill

1990 "El realce en tojolobal", en Nora C. England y Stephen R. Elliot, 1990: 461-471.

DAYLEY, Jon P.

1990 "Voz y ergatividad en idiomas mayas", en Nora C. England y Stephen R. Elliot, 1990: 335-398.

ENGLAND, Nora C., y Stephen R. Elliot, editores

1990 Lecturas sobre la lingüística maya, Centro de Investigaciones Regionales de Mesoamérica (CIRMA), La Antigua, Guatemala.

GómeZ HERnÁndeZ, Antonio, y Mario Humberto Ruz

1992 Memoria baldía. Los tojolabales y las fincas. Testimonios, Universidad Nacional Autónoma de México, IIF, Centro de Estudios Mayas, Centro de Estudios Indígenas, UNACH, México.

HiLl, Jane H.

1990 "Language, Culture and World View", en Frederick J. Newmeyer, 1990: 14-36.

Kaufman, Terence

1990 "Algunos rasgos estructurales de los idiomas mayances con referencia especial al k'iche'”, en Nora C. England y Stephen R. Elliot, 1990: 59-114.

LÁzaro CARreter, Fernando

1974 Diccionario de términos filológicos, $3^{\text {a }}$ edición, Editorial Gredos, Madrid.

LARSEN, Thomas W.

1990 "Notas sobre ergatividad en la gramática maya", en Nora C. England y Stephen E. Elliot, 1990: 319-334.

LENKERSDORF, Carlos

1991 ja yajk'achil sju'unil ja dyosi, vol. I, La Castalia, Comitán, Chiapas.

1993 ja yajk'achil sju'unil ja dyosi, vol. II, La Castalia, Comitán, Chiapas.

1994 Tojolabal para principiantes. Lengua y cosmovisión mayas en Chiapas, Centro de Reflexión Teológica, México.

MAXWELL, Judith Marie

1990 "El discurso en chuj", en Nora C. England y Stephen R. Elliot, 1990: 445-459. 
McCONELL-Ginet, Sally

1990 "Language and Gender", en Frederick J. Newmeyer, 1990: 7599.

NEWMEYER, Frederick J., editor

1990 Linguistics: The Cambridge Survey, IV Language: The Sociocultural context, Cambridge University Press, Cambridge, Nueva York.

OTro, Rudolf

1947 Das Heilige. Uber das Irrationale in der Idee des Göttlichen und sein Verhältnis zum Rationalen, 26 ${ }^{\mathrm{a}}$ edición, Biederstein Verlag, Munich.

Popol Wuj véase Saravia E., Albertina

RICCIARDI, Mirella

1991 Vanishing Amazon with Introductions by Marcus Colchester, Harry N. Abrams, Publishers, Nueva York.

SARAVIA E., Albertina

1992 Popol Wuj, antiguas historias de los indios quichés de Guatemala, advertencia, versión y vocabulario de Albertina Sarabia E., $13^{a}$ edición, Porrúa, México.

STAMMERJOHANN, Harro, editor

1975 Handbuch der Linguistik, Nymphenburger Verlagshandlung $\mathrm{GmbH}$, Munich. 